\title{
Particulate content of biogas
}

\author{
Richard Högström ${ }^{1, *}$, Hannu Vesala $^{2}$, and Martti Heinonen ${ }^{1}$ \\ ${ }^{1}$ VTT Technical Research Centre of Finland Ltd, Centre for Metrology MIKES, Tekniikantie 1, 02150 Espoo, Finland \\ ${ }^{2}$ VTT Technical Research Centre of Finland Ltd, Biologinkuja 5, 02150 Espoo, Finland
}

\begin{abstract}
Increased use of biogas in energy production and transportation is necessary to reduce greenhouse gas emissions and dependency of imported fossil fuels in the EU. To support this, quality specifications for biogas is under development specifying, among other things, limit values for impurities including the requirement of particle free biogas. At the moment, however, the particle concentration of biogas is not monitored. In this study, the need and appropriate methods for measurement based quality control was investigated. Biogas was sampled at the Kujala biogas production and upgrading facility in Lahti, Finland. Both off-line measurements of bottled biogas and on-site measurements were performed. Results indicate that the particulate content of biogas is very low even before any processing, and thus measurement based quality control is not necessary. However, the particulate content probably depends on the specific biogas production process and thus it must be assessed for each process separately. The measurement of particulate content of biogas should preferably be performed on-line, because sampling and storing biogas in gas bottles results in significant particle losses.
\end{abstract}

\section{Introduction}

In order to tackle global warming and reduce the dependency on imported fossil fuels, EU has issued a Renewable Energy Directive 2009/28/EC dictating that $20 \%$ of the energy consumption should come from renewable sources by 2020 [1]. Increased use of biogas in energy production and transportation is essential for reaching these goals.

To promote the use of biogas, a European standard CEN/TC 408 is under development which gives specification on the quality of biogas injected into natural gas grids and used as transport fuel. Among other parameters, limit values for key impurities are defined including the requirement that the produced biogas should be particle free [2]. At the moment, however, the particle concentration of biogas is not monitored.

Within the European Metrology Research Programme (EMRP) joint research project ENG54 Biogas, the need and appropriate methods for measurement based quality control of particulate content of biogas was investigated. In order to address these questions, the particulate content of biogas was measured at the Kujala production facility of GASUM in Lahti Finland using both on-line and off-line methods.

\section{Methods}

Many biogas production sites are quite small in terms of annual turnover, and hence there are limited resources for investing in measurement equipment. In practice, this implies using off-line measurement methods, which require sampling and storage of biogas in gas cylinders. Therefore, the feasibility of off-line analysis of particulate content was studied by sampling biogas into gas cylinders and analysing the particulate content in the laboratory.

\subsection{Composition of biogas}

The composition of raw (un-processed) biogas depends on the material from which it is produced and the type of production process. In the Kujala biogas production and upgrading facility, biogas is produced from bio-waste from households and industry by dry fermentation. The produced raw biogas is upgraded by high pressure water scrubbing (HPWS) in order to remove carbon dioxide and sulphates. The composition of the produced raw and processed biogas is shown in table 1.

Table 1. Composition of raw and processed biogas as determined by GASUM using gas chromatography.

\begin{tabular}{|c|c|c|}
\hline Composition & $\begin{array}{c}\text { Processed } \\
\text { biogas }\end{array}$ & $\begin{array}{c}\text { Raw } \\
\text { biogas }\end{array}$ \\
\hline Methane $\left(\mathrm{CH}_{4}\right)$ & $97.3 \%$ & $55.7 \%$ \\
\hline Carbon dioxide $\left(\mathrm{CO}_{2}\right)$ & $1.6 \%$ & $44.1 \%$ \\
\hline Nitrogen $\left(\mathrm{NO}_{2}\right)$ & $0.7 \%$ & NA \\
\hline Oxygen $\left(\mathrm{O}_{2}\right)$ & $0.4 \%$ & $0.1 \%$ \\
\hline Hydrogen sulfide $\left(\mathrm{H}_{2} \mathrm{~S}\right)$ & $0 \mathrm{ppm}$ & $5 \mathrm{ppm}$ \\
\hline
\end{tabular}

Corresponding author: richard.hogstrom@vtt.fi

(C) The Authors, published by EDP Sciences. This is an open access article distributed under the terms of the Creative Commons Attribution License 4.0 (http://creativecommons.org/licenses/by/4.0/). 


\subsection{Laboratory measurements}

Both raw and processed biogas was sampled into $50 \mathrm{~L}$ steel cylinders up to a pressure of 5 bar and 40 bar, respectively. The sample cylinders were evacuated before sampling and the connecting lines were kept as short as possible in order to avoid ambient air from entering the cylinder.

The particle concentration and size distribution was measured with an Electrical Low Pressure Impactor (ELPI) aerosol measurement instrument [3]. The ELPI was connected to the sample cylinder after a pressure reducer maintaining the inlet pressure at the ambient pressure level. The outlet was connected to a vacuum pump so that the outlet pressure was $10 \mathrm{kPa}$. The flow rate was set to $10 \mathrm{~L} / \mathrm{min}$. With these settings the following nominal impactor stage cut-off sizes were obtained: $0.028 \mu \mathrm{m}, 0.055 \mu \mathrm{m}, 0.093 \mu \mathrm{m}, 0.158 \mu \mathrm{m}$, $0.266 \mu \mathrm{m}, 0.387 \mu \mathrm{m}, 0.621 \mu \mathrm{m}, 0.959 \mu \mathrm{m}, 1.62 \mu \mathrm{m}$, $2.42 \mu \mathrm{m}, 4.04 \mu \mathrm{m}, 6.75 \mu \mathrm{m}$ and $10.02 \mu \mathrm{m}$. Greased alfoils were used as a substrate on the impactor stages in order to avoid particle bouncing. Before starting measurements, zeroing was performed in order to adjust the offset of the electrometers.

The particle concentration of raw and processed biogas was measured subsequently by changing the sampling line between the two sample bottles. In between and after the measurements, the background reading of the ELPI was checked by measuring laboratory air that has been sampled through a high efficiency particulate filter (HEPA). Also, the particle concentration of laboratory air was measured for comparison in order to get a grasp of the magnitude of the biogas particle concentration. Each measurement lasted for at least $10 \mathrm{~min}$.

\subsection{On-site measurements}

At the biogas production site, the ELPI was measuring at a location after the dry fermentation process, i.e. raw biogas was sampled. At this stage, the pressure level is quite low (1 mbar) and thus the ELPI could be connected to the process line without any pressure reducers in between. A Permapure Nafion ${ }^{\circledR}$ dryer (Dekati ${ }^{\circledR}$ Dryer DD-600) was connected at the input of the ELPI to remove water vapour from the gas in order to avoid water condensation at the ELPI impactor stages. Similar settings for the ELPI were used as in the laboratory measurements and zeroing was performed before starting measurements.

\section{Results}

\subsection{Laboratory measurement results}

The particle number concentration of processed biogas is very low and can barely be distinguished from the concentration of HEPA filtered laboratory air, which is practically particle free (figure 1). This is not surprising because the biogas upgrading process involves water scrubbing which effectively removes particles. Also a
1 micron particulate filter is included in the process for removing fine particles.

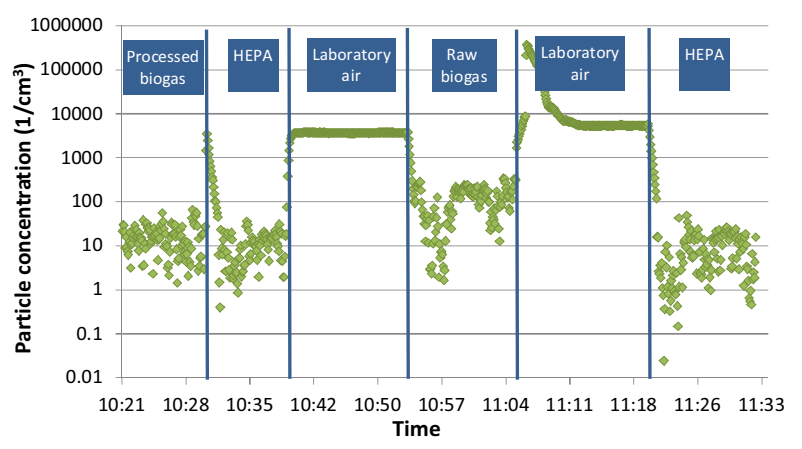

Fig. 1. Particle number concentration of raw and processed biogas as sampled from the sample cylinder. Particle concentration of laboratory air and HEPA filtered air is shown for comparison.

As expected, a higher particle concentration was found in raw (un-processed) biogas. However, the particle concentration is also very low (over one magnitude lower than the concentration found in laboratory air).

Based on the particle size distribution data (figure 2), most of the particles are below $100 \mathrm{~nm}$ in size. The concentration of particles larger than $100 \mathrm{~nm}$ is very low and cannot be distinguished from the background signal of the ELPI, which was measured by sampling HEPA filtered laboratory air. From figure 2 it can be seen that also processed biogas contains small amounts of particles in the size range below $100 \mathrm{~nm}$.

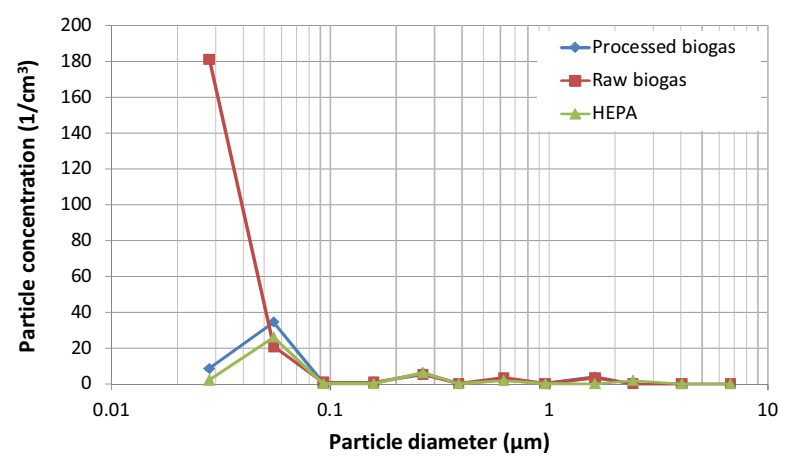

Fig. 2. Particle size distribution in bottled raw- and processed biogas. Results with HEPA filtered air is shown for comparison.

\subsection{On-site measurement results}

The particle concentration of raw biogas measured onsite (figure 3 ) is on average about 10 times higher than the concentration measured from the sample cylinder. 


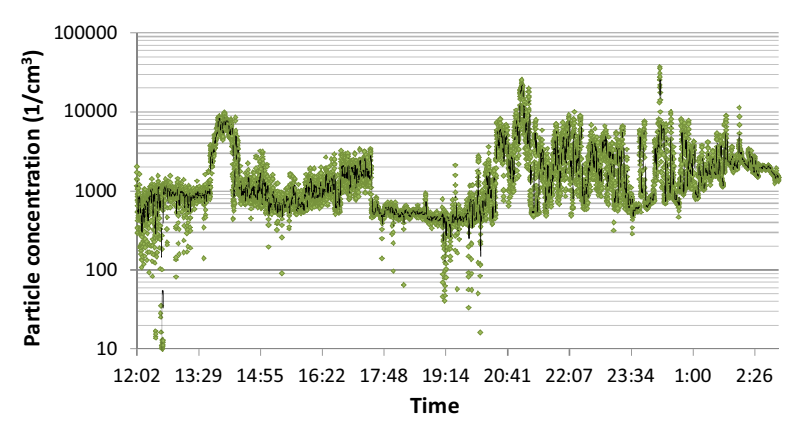

Fig. 3. Particle number concentration of raw biogas measured on-site. Solid line shows 1 min moving average.

This indicates that particulate losses caused by sampling and storing biogas into cylinders are considerable. Similarly to the laboratory measurements, most of the particles were below $100 \mathrm{~nm}$ in size (figure 4).

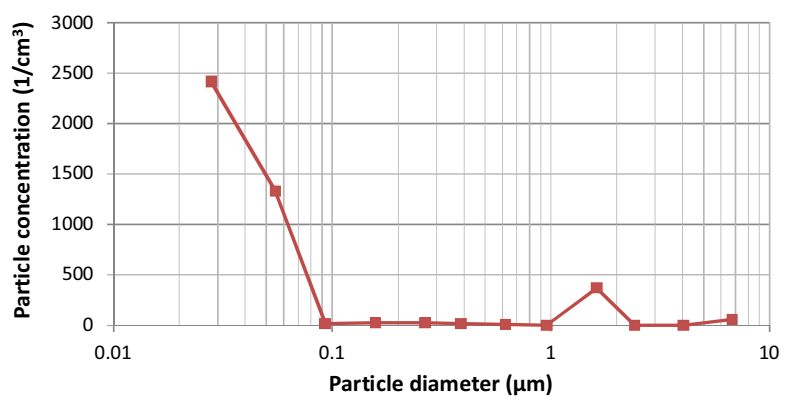

Fig. 4. Particle size distribution of raw biogas measured onsite.

Anyway, the particle concentration of raw biogas is on the order of 10 times lower than the particulate concentration of the air surrounding the site (measurements not shown here). This is reasonable considering that the dry fermentation process is an anaerobic process.

Although the average particle concentration of raw biogas is low, considerable temporal variations was observed. The reasons for these variations are not fully understood, but they are probably related to variations in the dry fermentation process.

\section{Discussion}

Offline measurements of particulate content of biogas are problematic due to particle losses in sample cylinders. Particles are lost by inertial impaction when filling the cylinder. Storage of the biogas in cylinders will lead to diffusional losses of fine particles onto the walls and losses of larger particles by gravitational settling. Therefore, it is recommended that the particle concentration of biogas is measured on-line. Moreover, on-site measurements using real-time aerosol measurement instrumentation, such as the ELPI, give an insight into the time dependent behaviour of the particle concentration in the process.

The particle concentration of biogas produced at the Kujala facility was found very low even before any processing. In any case, further processing is necessary to remove carbon dioxide and sulphur compounds so that the biogas can be used as a commercial fuel. This is achieved by the HPWS process, which effectively removes also particles. After this process, the biogas is sampled through a particulate filter. These process steps were found to effectively remove practically all particles from the biogas. Thus, at this specific facility, continuous particulate monitoring was found unnecessary. However, the particulate content probably depends on the biogas production process and therefore, the particulate content should be assessed for every process separately.

\section{Conclusions}

This study indicates that the particulate content of biogas is very low even before any processing. Based on these findings, measurement based quality control of particulate content is not necessary. However, the particle concentration probably depends on the production process, and therefore it should be assessed for every process separately. Measurements of particle concentration should preferably be performed on-line, because sampling into gas cylinders results in significant particle losses.

\section{Acknowledgements}

This work was supported by the European Metrology Research Programme (EMRP) jointly funded by the EMRP participating countries within EURAMET and by the European Union. The authors would like to thank Vesa Virtanen from GASUM for providing the biogas samples and for the assistance during the on-site measurements.

\section{References}

1. Directive 2009/28/EC of the European Parliament and of the Council on the promotion of the use of energy from renewable sources, Brussels, 23 April 2009

2. European Organization for Standardization, prEN 16723-2 - Natural gas and biomethane for use in transport and biomethane for injection in the natural gas network - Part 2: Automotive fuel specifications, 2014

3. J. Keskinen, K. Pietarinen, M. Lehtimäki, Electrical low pressure impactor, J. Aerosol Sci., 23(4), 353-360 (1992). 